Archives

$24 \mid 2000$

La séduction

\title{
Pour une histoire de la séduction
}

Journée d'étude du CRH - 16 janvier 1998

\section{Cécile Dauphin et Arlette Farge}

\section{(2) OpenEdition}

12 Journals

\section{Édition électronique}

URL : http://journals.openedition.org/ccrh/1892

DOI : $10.4000 /$ ccrh. 1892

ISSN : 1760-7906

Éditeur

Centre de recherches historiques - EHESS

\section{Édition imprimée}

Date de publication : 20 avril 2000

ISSN : 0990-9141

Référence électronique

Cécile Dauphin et Arlette Farge, "Pour une histoire de la séduction», Les Cahiers du Centre de

Recherches Historiques [En ligne], 24 | 2000, mis en ligne le 16 janvier 2009, consulté le 10 décembre

2020. URL : http://journals.openedition.org/ccrh/1892 ; DOI : https://doi.org/10.4000/ccrh.1892

Ce document a été généré automatiquement le 10 décembre 2020.

Article L.111-1 du Code de la propriété intellectuelle. 


\title{
Pour une histoire de la séduction
}

\author{
Journée d'étude du CRH - 16 janvier 1998
}

\section{Cécile Dauphin et Arlette Farge}

1 Souhaitant ouvrir un débat sur son questionnement dans le champ historiographique, le "Groupe d'histoire des femme" du CRH a organisé une journée d'étude le 16 janvier 1998, qui s'est déroulée en deux parties. La première a été centrée sur la lecture critique du livre De la violence et des femmes (Albin Michel, 1997) présentant les résultats de la précédente enquête du groupe. Cette mise en perspective a donné lieu à quatre contributions publiées dans Le Mouvement social, $\mathrm{n}^{\circ} 189$, octobredécembre 1999, p. 83-110).

2 La seconde partie de la journée a été consacrée à la définition d'un nouveau projet de recherche portant sur « la séduction ». Les Cahiers du CRH présentent ici des textes qui explorent différentes dimensions de la séduction dans ses usages politiques, anthropologiques et religieux (contributions de Hinnerk Bruhns, Jocelyne Dakhlia, Jean-Pierre Albert et Maurice Olender). En complément, l'article de Jean-Paul Desaive propose une étude de cas sur la séduction entre un maître et son apprentie.

Depuis cette rencontre, le Groupe d'histoire des femmes a poursuivi l'enquête sur la séduction. Les résultats paraîtront dans un livre collectif au début de 2001, aux éditions du Seuil. 